\title{
Cesariana seguida de abomasopexia pelo flanco esquerdo em novilha
}

Gilberto de Bona Foltran ${ }^{[a]}$, Rudiger Daniel Ollhofflb]"

${ }^{[a]}$ Cooperativa Agropecuária Videirense, Videira, SC, Brasil
${ }^{[b]}$ Pontifícia Universidade Católica do Paraná (PUCPR), Curitiba, PR, Brasil

*Autor correspondente

e-mail: ollhoff@gmail.com.br

\section{Resumo}

O deslocamento de abomaso é a principal causa de cirurgia abdominal em fêmeas leiteiras, ocorrendo normalmente no início da lactação, podendo também ser diagnosticado esporadicamente em qualquer estágio de lactação e/ou gestação. Normalmente está associado a doenças metabólicas e dietas com muito concentrado e pouca fibra, levando à baixa motilidade abomasal e consequente acumulo de gás. Pode se deslocar tanto para o lado esquerdo, quanto para o lado direito, sendo que $90 \%$ dos deslocamentos à esquerda ocorrem em vacas não prenhes, um evento incomum nas prenhas. Em atendimento veterinário ambulante, o primeiro autor foi chamado para atender a um caso obstétrico. Uma novilha mestiça Jersolando de $360 \mathrm{Kg}$, com 386 dias de primeira gestação, estava em trabalho de parto há 12 horas, segundo o proprietário. Após o toque vaginal, notou-se que o bezerro estava em apresentação anterior, posição estendida, no entanto, seu tamanho era incompatível com as vias fetais. Manobras obstétricas e tração foram realizadas sem sucesso, optando-se, então, pela cesariana via laparotomia pelo flanco esquerdo. 0 animal foi contido em estação e anestesiado, associando-se a anestesia regional em "L" invertido e epidural com $5 \mathrm{ml}$ de lidocaína. A incisão iniciava no segundo terço da fossa paralombar esquerda se estendendo $35 \mathrm{~cm}$ ventralmente. A pele, musculatura, peritônio e útero foram incisados de forma usual, sendo o bezerro retirado sem vida. A sutura do útero foi realizada com padrão invaginante dupla e uma contínua simples com fio de catgut número 3. Explorou-se a cavidade abdominal observando-se o abomaso localizado no quadrante médio do abdômen esquerdo, tendo como limite de sua curvatura dorsal a $11^{\text {a }}$ costela. Suturou-se de fio não absorvível nylon, $6 \mathrm{~cm}$ de comprimento na curvatura maior do abomaso em padrão removível, e após o esvaziamento do gás do abomaso foi realizada a abomasopexia (método de Utrecht), procurando fixar o órgão na parede 
abdominal ventral direita, ancorando-se o fio com o auxílio de duas estruturas arredondadas de borracha de $2 \mathrm{~cm}$ na parede externa. 0 fechamento do peritônio e musculatura foi feita com fio absorvível catgut 5, seguido pela pele, com fio não absorvível nylon pelo método contínuo de Ford. Após o procedimento, instituiu-se antibioticoterapia com cefalexina $10 \mathrm{mg} / \mathrm{Kg}$ e meloxicam $0,5 \mathrm{mg} / \mathrm{Kg}$, ambas se estendendo por 5 dias. Os pontos de pele e de fixação externa do abomaso foram retirados com 15 dias. Priorizou-se o manejo alimentar do animal após a cirurgia com alta quantidade de volumoso, aumentando o concentrado gradativamente. Não foi observada recidiva durante a lactação do animal. Outros casos de deslocamento de abomaso em vacas prenhas já foram descritos, porém concomitante com cesariana não há relato na literatura consultada. Chama-se atenção para a importância do exame palpatório minuncioso a ser feito em qualquer laparotomia. 